\title{
TEXTOS HUNI KUĨ
}

\section{Etnia Huni Kuĩ}

\section{Tradução de lbã Huni Kuĩ̃ e}

Maria Inês de Almeida**

Os Huni Kuĩ estão localizados no Brasil, no estado do Acre, e no Peru. Falam a língua Hatxã Kui e tem uma população de mais 10.000 pessoas no lado peruano e 2.500 do lado brasileiro.

1. Fonte: https://pib.socioambiental. org/pt/povo/kaxinawa

* Ibã Huni Kuĩ é txana, mestre dos cantos da tradição, pesquisador artista visual do grupo MAHKU - Movimento dos artistas Huni Kuĩ.

* Doutora em Comunicação e Semiótica pela PUC de São Paulo (1999), realizou pós-doutorado no Programa de Pós-Graduação em Antropologia Social da UFRJ. Pesquisa a experiência literária em território indígena e coordenou a área de Múltiplas Linguagens do curso de Formação Intercultural para Professores Indígenas da UFMG (200620011). Como diretora do Centro Cultural da UFMG criou o projeto Mira! Ares Visuais Con do Centro Cultural da U exposições e seminários com os artistas indígenas da América do Sul. 


\section{HAWE DAUTIBUYA/}

\section{FANTASIADA}

Hawe dautibuya

Vem fantasiada

Yube bau dauti

Fantasiada de jibóia

Yube isku hinari

Jibóia japó pena

Nai txà txã bururi

Céu muito riscado igual toco

Mabe tseme beime

Vem zoando acima da cabeça

Uke nai yukea

Vem do céu

Bake beru nãbuã

Os filhos mais jovens

Txi pia takuri

Bambuzinho novo
Si mane beime

Lá vem som muito lindo

Kete mana kãitã

O sopro saindo da boca

Txã mane beime

Vem com zoada som diferente

Dau kuma shetawe

Bico do Nambu

Nai kaya bixatã

Riscando no céu

Bi xapa baini

Risco do céu mais lindo. 


\section{HAWE MATSI KAWANAI/}

SENTE O FRIO PASSANDO

Hawe matsi kawanai dume kawanai

Sente o frio passando passando

Kawanai yanuri

Passando na mesma hora

Dume txina kawanai kawanai yanuri

Mel do tabaco passando na mesma hora

Dume kena data anã beime

Tabaco vem batendo no seu banco
Dume paxi bewanai bewanai dakan

Mareado do tabaco passando passando

Dume bai sheshame bai shesha dabeme

Caminho do tabaco tem duas bocas remendadas

Dume bama bename shupi nipa mixtime

Tabaco plantado não tem a folha estragada

Peshu nina beime

Vem com folha não estragada

Dume mia newãne mia newã dakani

Força do Tabaco bem colorida com várias cores

Dume muti keneya kekyanã beime

Tabaco vem batendo com seu tibungo colorido

Dume tepi keneya depi anã beime

Tabaco vem soprando no canudo desenhado no seu nariz

Dume putu deashnai deashnai dakani

Poeira do tabaco no nariz fazendo isso

Dume nisu bewanai bewanai dakani

Tonteira do tabaco passando passando 